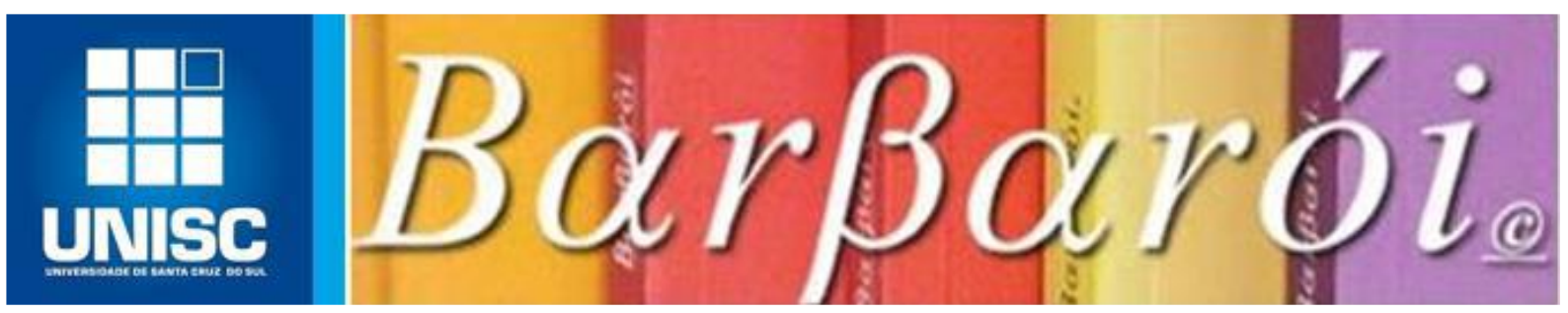

\title{
QUEM É O NOVO PAI? CONCEPÇÕES SOBRE O EXERCÍCIO DA PATERNIDADE NA FAMÍLIA CONTEMPORÂNEA
}

\section{DOI: http://dx.doi.org/10.17058/barbaroi.v0i57.14263}

\author{
Fernanda Torzeczki Trage \\ Universidade do Vale do Rio dos Sinos - UNISINOS - Brasil \\ Tagma Marina Schneider Donelli \\ Universidade do Vale do Rio dos Sinos - UNISINOS - Brasil

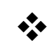

\section{Resumo}

O presente estudo tem como tema o papel paterno na atualidade. Para tal, definiu-se como objetivo geral compreender, a partir do olhar do novo pai, o exercício da paternidade na família contemporânea. Utilizou-se delineamento exploratório-descritivo, de abordagem qualitativa. Participaram desta pesquisa três pais, moradores da cidade de Porto Alegre/ RS e região metropolitana, que responderam os seguintes instrumentos: Ficha de Triagem, Ficha de Dados Sociodemográficos e Entrevista Semiestruturada. Com os dados coletados por meio da entrevista, realizou-se uma análise do conteúdo das falas dos participantes. Tal análise foi desenvolvida, tendo como base duas categorias: a percepção do entrevistado sobre o exercício da paternidade e a percepção do entrevistado sobre a paternidade na condição de filho. Os resultados apontaram que ser pai, na atualidade, afasta-se dos modelos tradicionais, uma vez que os pais exercem uma postura diferente com seus filhos da vivenciada na sua relação com seus progenitores. $\mathrm{O}$ pai contemporâneo mostra-se envolvido emocionalmente, mais participativo e comprometido, dividindo as tarefas de cuidado dos filhos e da casa com a esposa. A partir do ponto de vista do próprio pai, chegou-se a esses resultados, sendo possível compreender o exercício da paternidade na família contemporânea.

Palavras-chave: Paternidade, Novo pai, Contemporaneidade, Relações familiares.

\section{Introdução}

Ao se pensar a respeito da evolução histórica do papel do pai, é necessário levar em conta os movimentos sociais que acompanham as discussões sobre o papel da mulher na sociedade. Tal abordagem conduz a um movimento coletivo em prol dos direitos femininos, os quais se perpetuam em diferentes esferas sociais e impactam diretamente no núcleo familiar. Nesse sentido, concepções e conceitos configuram esses distintos momentos históricos da 
mulher e, por sua vez, das famílias. Negreiros e Féres-Carneiro (2004) estabelecem essas mudanças como "modelo antigo" e "modelo novo" de família. Costa (1983), Cúnico e Arpini (2013) e Roudinesco (2003) definem tais alterações na constituição familiar marcada por três fases: a tradicional, a moderna e a contemporânea ou pós-moderna.

Sob a ótica das concepções de família como "modelo antigo", está a demarcação da precisão de identidade de gênero ou das figuras masculinas e femininas, que apresentam características direcionadas em comportamentos, atitudes e interesses, num momento no qual o casamento é considerado indissolúvel e ligado à reprodução e ao papel da mulher como cuidadora do lar e dos filhos. Já o conceito de família pelo "modelo novo" traz uma marca identitária fluida, com a mulher participando ativamente do mercado de trabalho. Nessa ótica, a sexualidade não está atrelada obrigatoriamente à reprodução e os casamentos podem ser rompidos quando uma das partes desejar (NEGREIROS; FÉRES-CARNEIRO, 2004).

Embora apresentem termos distintos, Costa (1983), Cúnico e Arpini (2013) e Roudinesco (2003) consideram, nas três fases que estabelecem, os aspectos abordados por Negreiros e Féres-Carneiro (2004). Ao designá-las como tradicional, moderna ou contemporânea, concentram-se nas estruturações do núcleo familiar.

Quanto à família tradicional, os autores indicam que havia uma preocupação com a transmissão do patrimônio, e, por isso, os casamentos eram arranjados pelos pais dos noivos. A questão do amor e a vida sexual do casal não eram levados em consideração nessa época, havendo submissão da família frente à autoridade patriarcal. Já a família moderna, também designada de família nuclear ou família conjugal burguesa, emergiu junto a ascensão da burguesia do século XVIII, seguindo, justamente, o sistema de valores burgueses. Nessa fase, diferentemente da anterior, impera o amor entre os cônjuges, se estabelecendo uma relação hierárquica entre homens e mulheres. Os cuidados e o bem-estar dos filhos têm importância central nessa relação (COSTA, 1983; REIS, 2010; ROUDINESCO, 2003). A divisão de tarefas dentro do ambiente familiar colocou o homem como responsável pela produção, ou seja, pelo sustento do lar, enquanto a mulher era incumbida dos cuidados dos filhos e da casa (CÚNICO; ARPINI, 2013; REIS, 2010; SILVA, 2010).

Restrita à vida privada, a esposa ocupava, no modelo de família moderna, um papel de subjugação em relação ao cônjuge, uma vez que dependia jurídica, moral, econômica e religiosamente do esposo (BADINTER ${ }^{1}$, 1985; CÚNICO; ARPINI, 2013; ROUDINESCO, 2003; SILVA, 2010; STAUDT; WAGNER, 2008). A mulher, por ser responsável pelas

\footnotetext{
${ }^{1}$ Originalmente publicado em 1980.

Barbarói, Santa Cruz do Sul, n. 57, p.<141-164>,jul./dez. 2020
} 
atividades domésticas, passa a ser vista como um ser frágil e não apto à atividade intelectual, que abre mão de seus desejos e vontades para dedicar-se à família. A imagem do homem, em contrapartida, se mostrava como forte e vigorosa, ao desempenhar seu papel como provedor da família, inclusive na formação de valores morais (BADINTER ${ }^{2}, 1985$; COSTA, 1983; CÚNICO; ARPINI, 2013; REIS, 2010; ROUDINESCO, 2003; SILVA, 2010).

Tanto na estruturação do modelo de família tradicional ou moderna, a paternidade se revelava essencialmente por uma relação fria, distante e autoritária com os filhos, não havia manifestações de afeto. Era marcada pela ideia da diferença, calcada na hierarquia familiar, em que o adulto era detentor do saber, fazendo isso prevalecer através da sua autoridade. O pai desempenhava uma função educadora e disciplinadora, sendo simbolicamente importante para as crianças como modelo de poder e autoridade (BENCZIK, 2011; FREITAS; COELHO; SILVA, 2007; GABRIEL; DIAS, 2011; RAMIRES, 1997).

A família moderna calcava-se em um modelo de relações afetivas, sexuais e hierárquicas (CÚNICO; ARPINI, 2013; SILVA, 2010). A crise nessa configuração familiar instaurou-se na virada do século XX, pois o modelo da família burguesa seguiu trajetórias diferentes, produzindo efeitos distintos nas diversas classes sociais, fazendo com que a família se despatrimonializasse e a figura masculina perdesse sua rígida hierarquia de dominância (CÚNICO; ARPINI, 2013; PEREIRA, 2011; PERUCCHI; BEIRÃO, 2007; PETRINI, 2005; REIS, 2010; SILVA, 2010).

Esse cenário conduziu a mulher ao mercado de trabalho e trouxe questionamentos e reformulações quanto ao lugar da mulher na sociedade. Isso contribuiu para a expansão do movimento feminista, o qual levou, inclusive, ao desenvolvimento de métodos anticoncepcionais, bem como passou a considerar a possibilidade do divórcio (OLIVEIRA; PELLOSO, 2004; PEREIRA, 2003; RAMIRES, 1997; REIS, 2010; ROUDINESCO, 2003; SILVA, 2010). Tais fatos repercutiram diretamente na família, pois o desempenho da mulher como esposa e mãe estava ligado ao sucesso e ao prolongamento do casamento (CÚNICO; ARPINI, 2013; REIS, 2010).

A Constituição da República Federativa do Brasil de 1988 (GOLDANI, 1994) veio a consolidar o que os movimentos sociais almejavam: os princípios fundamentais para o ordenamento jurídico brasileiro. A partir desses princípios, dentre os quais o da cidadania e o da dignidade humana (art. $1 \S$, II e III), houve a reformulação de algumas concepções que orientavam as normas jurídicas no Brasil. Com a Constituição de 1988, aboliu-se a distinção

\footnotetext{
${ }^{2}$ Originalmente publicado em 1980.
}

Barbarói, Santa Cruz do Sul, n. 57, p.<141-164>,jul./dez. 2020 
entre filhos nascidos na constância do matrimônio e aqueles tidos fora do casamento, não havendo, assim, ilegitimidade de filhos tidos fora do casamento. Também se previu a igualdade de gênero, bem como o reconhecimento da união estável como forma de organização familiar (FONSECA, 2005; PEREIRA, 2011).

Permeada por essas mudanças é que se constitui a família contemporânea ou pósmoderna, na qual passa a ser admissível o rompimento entre os pares; ou seja, o casamento não é considerado mais um pacto familiar indissolúvel. No momento em que o afeto, o companheirismo, os desejos e os objetivos em comum estejam em discordância, é possível romper o casamento (CÚNICO; ARPINI, 2013; PEREIRA, 2011; ROUDINESCO, 2003; SPENGLER, 2012).

Esses novos direitos adquiridos pelas mulheres trouxeram à tona comportamentos sociais que revelaram novas configurações familiares e, frente à possibilidade de divórcios, separações e recomposições conjugais, o exercício da maternidade e da paternidade implicaram em novas funções, as quais não mais apresentam uma ideia fixa de pai provedor e de mãe incumbida da família e dos cuidados domésticos. O novo cenário conduziu a uma maior igualdade de tarefas e responsabilidades entre os membros da família (GRZYBOWSKI, 2002; RAMIRES, 1997; ROUDINESCO, 2003; SILVA, 2010; SOARES, 2008; WAGNER, 2002).

Diante dessa nova estruturação familiar, com mães ocupadas profissionalmente e não dedicadas exclusivamente ao lar, alterou-se também o papel exercido pelo homem no contexto da família, tanto na dinâmica dos cuidados com a casa quanto no exercício da paternidade, sendo, assim, necessária sua dedicação aos filhos, bem como às tarefas domésticas (CREPALDI et al. 2006; OLIVEIRA; PELLOSO, 2004; RAMIRES, 1997; SOUZA; BENETTI, 2009; VIEIRA et al., 2014). Assim, as transformações ocorridas nas famílias repercutiram para um novo delineamento dos papeis maternos e paternos na contemporaneidade.

Diferentemente do modelo tradicional de paternidade, o pai da atualidade, nessa estrutura familiar contemporânea ou pós-moderna, é demandado socialmente para que exerça uma paternidade mais implicada e ativa no que se refere à convivência e aos cuidados com os filhos (BOSSARDI; VIEIRA, 2010; GOMES; RESENDE, 2004; RAMIRES, 1997). Os estudos que buscam definir as funções paternas na família e no desenvolvimento infantil, contudo, não apresentam um consenso do que predomina como característica na paternidade de hoje. Bossardi e Vieira (2010) indicam que a diferença da paternidade pós-moderna para a moderna consiste em uma manifestação mais explícita de sentimentos dos pais com os filhos, assim como um contato físico mais próximo e íntimo. 
O modelo de paternidade contemporâneo é chamado, segundo Bolze e Crepaldi (2015), de emergente. Nele, identifica-se que há uma pluralidade de modos de ser pai e isso não pode ser entendido apenas com base na sua relação com a família de origem: “O jeito de ser pai será sempre muito particular de cada um e estará relacionado à história de vida, a características individuais e a processos familiares, às necessidades que surgirem pelo caminho, ao contexto social e à cultura" (BOLZE; CREPALDI, 2015, p. 40).

O novo pai - termo também utilizado para referir-se ao pai contemporâneo e que será adotado para designá-lo neste trabalho - deseja reformular a sua experiência vivida na infância, considerando-se mais feliz e realizado com o ativo envolvimento no cuidado e educação dos filhos. A sua ausência é apontada em prejuízos no processo de ensino-aprendizagem, no desenvolvimento moral e na formação da identidade de gênero (GOETZ; VIEIRA, 2009; RAMIRES, 1997; SILVA; PICCININI, 2007; VIEIRA et al., 2014). Diante dessas novas atribuições, Staudt e Wagner (2008) indicam que muitos homens passaram a vivenciar a paternidade de forma distinta do modelo constituído na relação com o seu próprio pai.

As autoras ainda salientam que, apesar dessa nova estruturação de papéis, muitos homens ainda não se envolvem tão ativamente em tarefas domésticas e de cuidado com os filhos. Indicam que isso está associado a crenças relacionadas ao fato de o cuidado estar vinculado ao gênero feminino. Além disso, é evidenciado o aspecto biológico da mulher, uma vez que a relação com os filhos se estabelece já no ventre materno e apenas sua fisiologia é apta a amamentar. Relaciona-se a gestação e a lactação, por serem exclusividade da mulher, à condição instintiva e natural de estar mais bem preparada para desempenhar a função do cuidar. Bossardi e Vieira (2015) também trazem essa perspectiva, salientando, por sua vez, que as marcas biológicas femininas, ao estabelecer relação mãe-bebê, reforçam socialmente o papel da mulher como cuidadora.

Diante disso, salienta-se que, apesar das especificidades fisiológicas femininas, o homem pode, sim, desempenhar um papel ativo nos cuidados com os filhos. Cabe, portanto, sustentar esse lugar de efetiva participação, o que implica na revisão de crenças e valores que pautam e permeiam nossa cultura (CÚNICO; ARPINI, 2013; STAUDT; WAGNER, 2008). Nesse sentido, para que se realize um bom ajustamento quanto às tarefas e às funções familiares, é necessário que os cônjuges consigam compartilhar responsabilidades enquanto pais, implicando num envolvimento conjunto e de reciprocidade dos pais na educação dos filhos (BOSSARDI; VIEIRA, 2015). 
Há diversas teorias que buscam compreender o papel do pai: a perspectiva sistêmica visa observar o fenômeno por meio de uma abordagem integral e contextualizada; a teoria psicanalítica se orienta na compreensão psíquica simbólica do sujeito; a perspectiva evolucionista integra o percurso filogenético e ontogenético. Além disso, há a perspectiva geracional, ou seja, observando-se as continuidades e as distinções nos papeis de uma geração para a outra, numa mesma família. Sob essa ótica, considerando o comportamento paterno, Bolze e Crepaldi (2015) reforçam que há uma tendência a se reproduzir os modelos aprendidos na infância. Destacam, contudo, que a participação mais ativa da mulher no mercado de trabalho conduziu os homens a papeis mais participativos na esfera familiar, o que, de certo modo, levou a uma descontinuidade nos padrões geracionais tradicionais. Indicam, em contrapartida, a dificuldade que se tem em romper padrões, especialmente os modelos geracionais negativos (BOLZE; CREPALDI, 2015).

Em pesquisa realizada pelas autoras, elas identificaram que a maior parte dos pais ${ }^{3}$ afirmou agir com seus filhos de modo semelhante ao comportamento recebido na infância por seus pais. Eles expuseram que a inspiração paterna está relacionada ao zelo, a explicações sobre o que é certo e o que é errado, além do respeito a outras pessoas. $\mathrm{O}$ fator de primazia apontado por esses pais está no incentivo à educação, o qual indicam reforçar com seus filhos.

Maternar é o verbo utilizado na designação do exercício da paternidade atual, quando o homem se comporta para cuidar e atender às necessidades da criança (RAMIRES, 1997). Abade e Romanelli (2018) sinalizam que o maternar não se configura como intuição feminina, mas está vinculado a aprendizados sociais e culturais construídos com base em normas que são modificadas de acordo com o contexto histórico. Nessa perspectiva, o pai pode aprender a desempenhar seu papel como cuidador do mesmo modo que ele é aprendido pela mãe.

$\mathrm{O}$ conceito trazido pelos autores vem ao encontro da abordagem apresentada por Ramires (1997), a qual indica que a maternidade e a paternidade transcendem o aspecto biológico, alcançando um estatuto psicológico e social. $\mathrm{O}$ ato de gestar, dar à luz ou amamentar não garantem a experiência da maternagem, assim como as peculiaridades do gênero masculino não estão vinculadas à capacidade do cuidar, podendo exercer, assim, também, na plenitude, a maternagem.

As mudanças nas configurações familiares têm despertado o interesse de pesquisadores sobre a participação paterna nos cuidados dos filhos. Embora ainda seja pouco explorada a

\footnotetext{
${ }^{3} \mathrm{O}$ termo pais, quando se referir ao pai e mãe, será indicado no texto, no formato a seguir: pais (pai e mãe); caso não haja indicação, a acepção da palavra designa pai ou pais - relativo à paternidade.
} 
atuação do pai no cotidiano das crianças na primeira infância, há autores como Bossardi e Vieira (2010) e Fleck e Wagner (2003) que trazem em seus estudos a importância dos pais na constituição psíquica da criança, especialmente dos bebês, e que se apresentam tão capazes quanto as mães de exercerem as funções de cuidado e educação.

Bossardi e Vieira (2015) esclarecem que o cuidado paterno pode ser entendido tanto por fatores ligados a aspectos evolutivos quanto culturais. Entre os evolutivos estão a oportunidade de acasalamento, a certeza de paternidade e a sobrevivência da prole. Já aspectos culturais integram a própria necessidade e vontade de equalizar as funções maternas e paternas. Sinalizam, no entanto, que o investimento parental não é desempenhado igualmente pelo pai e pela mãe, uma vez que há diferenças estabelecidas por fatores culturais e contextuais: "Fatores como idade, sexo e número de filhos, satisfação conjugal, experiências estressantes na infância e condições de vida são atrelados à intensidade desse investimento" (BOSSARDI; VIEIRA, 2015, p. 22).

A literatura indica que o pai da atualidade, ou o novo pai, como abordam Goetz e Viera (2009), não apresenta, em geral, um modelo específico, mas, sim, há coexistência entre o modelo de pai tradicional e o modelo de pai contemporâneo. Tal característica é entendida pelos autores como positiva, uma vez que o modelo tradicional, de pai provedor, o qual proporciona segurança e autoridade, se soma aos aspectos emocionais do pai contemporâneo, que se caracteriza pelo envolvimento afetivo com os filhos e com a esposa, assim como atua de forma mais ativa nas tarefas do lar (BENCZIK, 2011; FREITAS; COELHO; SILVA, 2007; GABRIEL; DIAS, 2011; RAMIRES, 1997).

Esse novo pai, contudo, que tem o papel de provedor e, ao mesmo tempo, participativo nas atividades de casa e engajado emocionalmente com a família, embora seja identificado como o pai ideal, nem sempre consegue sustentar essa condição (BELTRAME; BOTTOLLI, 2010). Por conta da intensa carga horária de trabalho, por exemplo, muitos pais referem não conseguir exercer um papel tão ativo na divisão das tarefas de cuidados dos filhos com a esposa.

Sob essa ótica que se torna importante compreender os aspectos que caracterizam o envolvimento paterno. Tal conceito é abordado nas pesquisas de Lamb et al. (1985), os quais o estruturam sob três dimensões de avaliação com base no comportamento do pai, são elas: interação, acessibilidade à criança e responsabilidade. A primeira envolve a interação do pai de forma direta com o filho - ao cuidar, brincar e envolver-se em atividade de lazer; a segunda consiste na disponibilidade desse para com o filho para possíveis interações entre ambos; a terceira refere-se ao pai responsabilizar-se pelo cuidado, ou seja, o pai como principal cuidador 
da criança. Esse compromisso paterno, no qual há um maior envolvimento emocional e com as demandas de rotina do filho, é indicado por Vieira et al. (2014) como um fator de proteção para o desenvolvimento da criança.

Nesse sentido, Parke (1996 apud CASTOLDI; GONÇALVES; LOPES, 2014) apresenta, em seu estudo, os elementos que podem contribuir para o envolvimento paterno com o filho: questões internas do pai, como, por exemplo, experiências próprias da sua paternidade; contexto sociocultural; qualidade da relação conjugal; percepções sobre o seu papel como pai, assim como a percepção da esposa sobre a atuação do marido na função paterna. Tais fatores são identificados pela autora como itens que influenciarão no comportamento do pai quanto à participação nos cuidados do filho ou até mesmo na condição de principal cuidador.

Bolze e Crepaldi (2015) indicam, com base em seus estudos, que há três fatores principais aos quais os pais devem se atentar ao terem o intuito de desenvolver a atividade paterna com qualidade. O primeiro está em buscar manter uma relação cordial com sua família de origem; o segundo consiste no empenho que deve ter para que consiga estabelecer uma relação conjugal na qual haja uma comunicação aberta, bem como possibilidades construtivas para a resolução de conflitos; o terceiro fator está no engajamento na vida da criança desde o período gestacional, acompanhando de perto todas as fases desenvolvimentais do bebê.

Em estudos sobre a participação paterna, o pai tem se mostrado como principal fonte de apoio social para a mãe, e tal característica está estabelecida desde a gestação até os cuidados com o bebê após o nascimento (RAPOPORT; PICCININI, 2006; SILVA; PICCININI, 2007). A participação paterna aparece como uma forma de proteção para a mãe, pois, ao se sentir segura, ela consegue estabelecer um bom vínculo com o bebê. Esse apoio é percebido diante das manifestações de carinho, encorajamento e assistência recebidos por parte do parceiro.

O apoio conjugal é apontado, inclusive, como uma influência indireta no bem-estar psicológico e no comportamento de ambos, enquanto pais (pai e mãe). Acredita-se que diante do apoio, conselhos e assistência oferecidos pelo parceiro, a tendência é que o cônjuge não sinta de forma tão estressora os eventos adversos vivenciados em suas vidas (RAPOPORT; PICCININI, 2006). Os autores sinalizam que o engajamento paterno pode ser prejudicado se houver situações oriundas de fortes conflitos conjugais e isso pode comprometer relações futuras da criança com amigos, familiares e cônjuge. Nesse sentido, a relação dos pais (pai e mãe) também afeta e ajuda a regular o comportamento social das crianças. Os relacionamentos íntimos em sua adultez estão ligados à experiência que tiveram com a família de origem (BOLZE; CREPALDI, 2015). 
A participação paterna como fonte de apoio para a mãe também foi avaliada como uma influência positiva no desenvolvimento do apego entre mãe e bebê (RAPOPORT; PICCININI, 2006). Destaca-se que, conforme Castoldi, Gonçalves e Lopes (2014), a mãe se sente amparada pelo companheiro quando o pai tem o papel de provedor no sustento familiar, sendo o principal responsável pelas despesas da casa, o que é visto, pela mulher, como um pai que possui envolvimento e comprometimento com seus filhos e esposa. Tal perspectiva vem ao encontro das abordagens sobre o "novo pai", o qual, mesmo tendo caraterísticas próprias do modelo contemporâneo, mantém aspectos que ainda estão pautados no modelo tradicional.

O estudo qualitativo realizado por Krob, Piccinini e Silva (2009), voltado ao comportamento dos pais no período gestacional até o segundo mês de vida do bebê, trouxe resultados que evidenciaram que quando o pai não sentia, por parte da esposa, uma abertura para tomada de uma posição frente aos cuidados do filho e/ou se sentia em desaprovação, tendia a não estabelecer uma relação de cuidado, exercendo assim uma relação tradicional com o bebê. Tal aspecto remete aos conceitos de envolvimento paterno abordados por Lamb et al. (1985), em especial o que ele designa como disponibilidade, na medida em que o sentimento de desaprovação da esposa no exercício da paternidade do marido pode inibir uma interação mais intensa entre pai e filho.

Castoldi, Gonçalves e Lopes (2014), ao também investigarem o comportamento dos pais $^{4}$ em período gestacional até o primeiro ano de vida do bebê, apontaram que, a partir das aquisições motoras que o bebê tem, o pai tende a engajar-se mais nos cuidados com o filho, buscando uma construção de vínculo entre pai-bebê. O pai, ao notar que o bebê já possui certa firmeza de movimentos, sente-se mais confortável a desempenhar as tarefas de cuidado.

Em relação aos sentimentos paternos frente à experiência de se tornar pai, o estudo de Gonçalves et al. (2013) indicou que a experiência frente à paternidade era demarcada por satisfação e sentimentos positivos. Tal pesquisa, concentrada em bebês até o terceiro mês de vida, apresentou pais que manifestaram desejo de participar ainda mais da vida dos filhos, embora tenham destacado que o cotidiano de cuidado com os filhos pode ser bastante cansativo.

Frente a esse cenário, ao se considerar essa nova organização social, a qual impacta diretamente na dinâmica familiar, identifica-se a necessidade de trazer a figura paterna para o centro das investigações. Ao se entender seu posicionamento e os aspectos que caracterizam essa nova conjuntura, torna-se possível atuar, enquanto psicóloga, de forma mais assertiva, na

\footnotetext{
${ }^{4} \mathrm{O}$ termo pais neste estudo abrange a função materna e paterna. Nesta investigação, apenas se trouxe os resultados referentes ao pai.
} 
medida em que se reconhece as demandas do núcleo familiar no contexto atual. Com base nessa premissa, definiu-se como objetivo desta investigação compreender, a partir do olhar do novo pai, o exercício da paternidade na família contemporânea.

\section{Método}

Delineamento

Desenvolveu-se um estudo de caráter exploratório-descritivo, de abordagem qualitativa. Participantes

Participaram do estudo três pais, os quais foram acessados por conveniência (SAMPIERI; COLLADO; LUCIO, 2013). O perfil de participantes determinados para esta investigação consistiu em pais que se ocupassem diariamente dos cuidados dos filhos, dividindo e auxiliando nas tarefas de alimentação, troca de fraldas, hábitos de higiene, participando ativamente das decisões referentes ao filho. A família deveria residir em Porto Alegre/RS ou região metropolitana. Os critérios de exclusão foram: o pai ter idade inferior a 18 anos e/ou possuir patologias ou outros comprometimentos que impedissem a participação nos procedimentos da pesquisa.

Os participantes receberam nomes fictícios para preservar suas identidades. Na Tabela 1, apresenta-se a descrição dos participantes.

Tabela 1 - Dados dos participantes

\begin{tabular}{ccc}
\hline Pai A - Arthur & Pai B - Bruno & Pai C - Carlos \\
\hline 37 anos & 33 anos & 34 anos \\
Advogado; pós-graduado & Advogado; pós-graduado & Empresário; pós-graduado \\
Casado com Ana há 5 anos & Casado com Bárbara há 1 & Casado com Cristiane há 4 \\
arimeiro filho do casal & Primeiro filho do casal & anos \\
Bebê Ângelo - 1 ano e 3 & Bebê Bento - 5 meses & Bebê Caio - filho do cas ês e 7 dias \\
meses & & \\
\hline
\end{tabular}

Fonte: Elaborado pela autora.

\section{Instrumentos e procedimentos de coleta de dados e éticos}

A proposta deste estudo foi divulgada por meio de uma postagem de um folder digital, nas redes sociais da autora, a qual também foi compartilhada por suas redes de contatos. Dessa forma, obteve-se a manifestação inicial por parte dos interessados em participar da pesquisa. 
Posteriormente, realizou-se contato telefônico, a fim de explicar os objetivos da investigação, reforçar a garantia quanto aos direitos de sigilo e do caráter voluntário em participar do estudo, assim como verificar os critérios de inclusão e exclusão da pesquisa. Esse primeiro procedimento definiu-se como entrevista de triagem e para qual se utilizou a Ficha de Triagem.

A partir disso, marcou-se um encontro presencial com o participante no consultório de atendimento clínico particular da pesquisadora. $\mathrm{Na}$ ocasião, primeiramente realizou-se a assinatura do Termo de Consentimento Livre e Esclarecido (TCLE) e, a seguir, preencheu-se a Ficha de Dados Sociodemográficos para se obter dados gerais sobre o pai.

Por último, realizou-se uma entrevista semiestruturada, com base no Roteiro de Entrevista Semiestruturada, com vistas a descrever e avaliar a relação do entrevistado com o seu pai, a forma como percebe o exercício da paternidade na família contemporânea, bem como o redimensionamento do papel paterno e seus sentimentos diante da sua atuação de pai. Além desses aspectos, foram abordadas ao longo da entrevista perguntas relacionadas ao período gestacional da esposa, o envolvimento paterno nos cuidados com o filho, a compreensão do pai a respeito dos estados mentais do bebê e questões referentes ao relacionamento conjugal do casal. Essas questões não foram analisadas neste trabalho. As entrevistas foram gravadas e posteriormente transcritas.

Salienta-se que o projeto de pesquisa foi submetido ao Comitê de Ética em Pesquisa da UNISINOS, sob o n ${ }^{\text {o }}$ CAAE CAAE 90968418.8.0000.5344, o qual obteve aprovação (Resolução 2.719.548), pois cumpriu com as exigências éticas e metodológicas esperadas de uma pesquisa que envolve seres humanos.

\section{Procedimento de análise dos dados}

Para análise dos dados deste estudo realizou-se uma avaliação individual dos dados obtidos em cada caso. Foram utilizados, para isso, a Ficha de Dados Sociodemográficos, a fim de confirmação de dados pessoais dos participantes e de caracterização dos participantes, e o Roteiro de Entrevista Semiestruturada, o qual propiciou uma análise de forma global, qualitativamente, sobre o conteúdo das falas dos participantes.

Nessa perspectiva, elegeu-se duas categorias de análise: a percepção do entrevistado sobre o exercício da paternidade, para entender de que forma ele compreende o seu papel paterno, bem como seus sentimentos em relação ao seu lugar de pai; e a percepção do entrevistado sobre a paternidade na condição de filho, para compreender a atuação do pai do entrevistado, verificando as influências que o modelo exerce na sua atuação como pai. 


\section{Resultados e discussão}

\section{Descrição dos participantes}

Arthur, 37 anos, é casado há 5 anos com Ana, 35 anos; são pais de Ângelo, de 1 ano e 3 meses, fruto de uma gravidez muito desejada e planejada por ambos. Arthur relatou que sempre desejou ser pai, narrando com alegria a lembrança do momento em que realizaram o exame para detecção da gravidez, bem como a felicidade que sentiram quando de seu resultado.

O participante Bruno, de 33 anos, casou-se há 1 ano com Bárbara, 25 anos, quando soube da gravidez de Bento. O filho do casal tem 5 meses. Bruno relata que seu relacionamento com Bárbara estava em estágio inicial, quando souberam que teriam um filho; apesar de ele desejar ser pai, conta que a notícia o deixou surpreso. Para Bruno, o período gestacional de Bárbara fez com que o relacionamento se intensificasse.

Carlos, 34 anos, é casado há 4 anos com Cristiane, 33 anos. A união dos dois resultou no nascimento de Caio, com 1 mês e 7 dias. Carlos relata que a vontade maior de ter um filho partiu dele, afirmando que Cristiane nunca manifestou claramente o seu desejo em tornar-se mãe. Houve muito planejamento do casal para a concretização da gravidez, destacando a conclusão de etapas consideradas importantes para a vida profissional de ambos.

\section{Percepção dos entrevistados sobre o exercício da paternidade}

Em relação à categoria percepção do entrevistado sobre o exercício da paternidade, o desejo de tornar-se pai foi referido por todos os participantes. No caso de Arthur e Carlos, o desejo tornou-se um planejamento de vida para o casal e uma espera, a qual foi repleta de expectativas. A confirmação da gravidez trouxe sentimentos de "alegria", "felicidade", "concretização de desejo" e, no caso de Bruno, inicialmente, "surpresa", pois se encontrava em início de relacionamento com a companheira, quando souberam que seriam pais. Os participantes atribuíram ao desejo de tornarem-se pais a postura participativa: "Eu sempre quis ter filho, então nada mais justo que eu me fazer presente" (Bruno, 33 anos).

A postura participativa dos pais iniciou já no período gestacional das esposas, ficando claro o empenho físico e emocional ao longo de todo o período da gestação. Arthur relata que esteve ativamente presente no período de gestação de Ana, acompanhando-a em consultas médicas, auxiliando-a em atividades de organização da casa e da rotina do casal. Relembra, inclusive, as duas últimas semanas que antecederam o nascimento de Ângelo, quando Arthur passou a levar a esposa até o local de trabalho. 
Apresenta dados da sua participação na rotina do casal em prol da gravidez: "Assim, no dia a dia, tu ia percebendo que as coisas tavam indo bem. A saúde da Ana tava boa [...] E eu me envolvi também; eu gosto de cozinhar, então ela me dava a lista do que ela precisava comer e eu ia no supermercado, aí eu fazia as coisas pra ela comer...” (Arthur, 37 anos). Destaca-se que tal apoio por parte do pai, já no período gestacional, reflete-se de forma muito importante para a mãe, fazendo com que ela se sinta mais amparada e segura, encorajando-a a exercer o seu papel - isso irá influenciar positivamente no vínculo a ser constituído com o bebê (RAPOPORT; PICCININI, 2006; SILVA; PICCININI, 2007).

Arthur deixa bem explícito em sua narrativa o quanto as suas expectativas iam crescendo na medida em que o tempo gestacional ia passando, demostrando seu engajamento ao longo de toda a gestação, expondo uma conduta, de fato, participativa. Identifica-se também seu envolvimento emocional, ao explicitar sua angústia e expectativa quanto à saúde do bebê.

No diálogo, se evidencia as preocupações que os pais tinham em razão dos cuidados a serem desempenhados com os filhos. Bruno, por sua pouca experiência com bebês, questionava-se: "se ele ficar doente, o que eu vou fazer? [...] se eu tiver que trocá-lo, o que eu vou fazer? [...] e se ele chorar de noite?...". Na mesma perspectiva, Arthur narra: “existia assim, no início, aquela ansiedade, como que vou passar a ser pai, tanto eu ser pai quanto se eu ia conseguir entender o que o Ângelo queria".

Arthur narra sobre a primeira noite, como a dificuldade materna em amamentar, assim como sua atuação ao tentar acalmar Ângelo, mantendo-o no colo. Traz à lembrança a primeira troca de fraldas e resgata, pela memória sensorial, de que pegava na barriguinha de Ângelo, a qual, por seu tamanho, preenchia a sua mão - e que hoje seu filho cresceu. Fala, com entusiasmo, de suas primeiras condutas como pai: "eu pegava ele todo desajeitado".

Os elementos reforçam as inseguranças que muitos pais têm em cuidar de bebês; as crenças estão vinculadas ao fato de o cuidado de crianças pequenas estar associado a melhores desempenhos das mulheres, segundo Staudt e Wagner (2008), o qual é reforçado, ainda, pela condição da gestação e do amamentar, visto que são funções de exclusividade da mulher. Isso leva a crer que a mulher se encontra mais apta a desempenhar os cuidados de recém-nascidos.

Carlos, ao ser questionado sobre a sua atuação paterna, relatou que se sentia tranquilo. Conta que, por insistência da esposa, eles participaram de um curso preparatório para pais antes do nascimento de Caio:

"Eu nunca tive nenhum receio, acho também que pro homem é mais fácil, né, a mulher, que acaba sofrendo todas essas mudanças no corpo e pro homem talvez não tenha tanta, seja natural, não tenha tanta preocupação. Eu sabia que a hora que ele 
fosse nascer eu ia dar meu jeito, né, ia procurar informação, ia fazer as coisas darem certo, mas assim, não tive assim nenhuma preocupação de perde sono, né”.

Os elementos apresentados vem ao encontro das considerações de Staudt e Wagner (2008), mencionadas anteriormente, sobre a ideia de aptidão feminina para a maternidade: Carlos parece reforçar essa crença, não se sentindo preocupado pelo nascimento do filho, pois sua esposa saberia conduzir os cuidados e, quando ele fosse solicitado, caso não soubesse, buscaria informação. Manifesta, inclusive que, logo após o nascimento de Caio, buscou informações a respeito do bem-estar do bebê e montou uma rotina de cuidados para o casal.

O relato de Arthur revela um comportamento que Ramires (1997) designa de maternar, uma vez que indica desempenhar atividades de cuidado com o filho, sendo sensível, responsivo e afetuoso nas ações com ele. Traz detalhadamente episódios dos primeiros meses de vida de Ângelo, de como lidava com os problemas gastrointestinais do bebê, e de como sabia conduzir a situação para acalmá-lo: "ele tinha problema na barriga, gases, eu sabia o jeitinho que ele parava, ficava um pouquinho melhor, acalmava ele". A lembrança de Arthur é permeada por sentimentos afetivos, demonstrando ser um pai carinhoso, amoroso e atencioso - elementos essenciais para que se construa a personalidade do filho.

As condutas de maternar também são percebidas na postura de Bruno, ao expor a forma como auxilia a esposa nos cuidados do filho: “eu ajudo a trocá-lo, eu ajudo a dar banho, ajudava a pegar ele pra colocar no seio, na hora de mamar... dou uma nanadinha pra ele dormir, essas coisas...”. A conduta sensível e o envolvimento emocional do pai ao cuidar de seus filhos são destacados como um fator de proteção para o seu desenvolvimento. Crianças que têm experiências positivas com o pai apresentam melhores níveis de desempenho escolar, melhores habilidades sociais, são mais empáticas (RAMIRES, 1997; SILVA; PICCININI, 2007; VIEIRA et al., 2014).

Os pais mostraram-se satisfeitos em participar ativamente das tarefas de cuidado dos filhos. Carlos manifestou explicitamente isso: "eu queria ter uma participação nos primeiros dias, no crescimento dele, né". Bruno destaca o seu envolvimento nos cuidados de Bento como sendo uma obrigação e dever de todo o pai que quer ser presente na vida do filho: "foi um negócio de obrigação, de dever, porque acima de tudo eu amo muito ele, meu filho. Então, não tinha como ser diferente". Os dados corroboram as evidências citadas nos estudos de Ramires (1997), Silva e Piccinini (2007) e Vieira et al. (2014), que indicam o desejo de o pai estar ativamente envolvido nos cuidados e na educação dos filhos. 
Para Bruno, a chegada de Bento representou uma nova tomada de papéis, de novos planejamentos de vida, sendo necessária uma adequação em razão do novo integrante da família. Pelo fato da pouca experiência com bebês por parte do casal, Bruno destaca que: "a gente tá aprendendo um com o outro a sermos pais do Bento".

Arthur narrou a rotina que fora construída pelo casal para cuidar e acolher o filho e que "tudo foi sempre em conjunto", ou seja, o casal reestruturou-se em prol da criança. Os relatos demonstram a condição, citada por Bossardi e Vieira (2015), de coparentalidade, uma vez que na entrevista deixa claro o diálogo e a organização coletiva do casal frente às demandas do filho.

A coparentalidade apresenta-se como uma característica da família contemporânea, sendo observada também nos outros dois casos, os quais indicaram uma negociação de responsabilidades entre os casais. A reestruturação na vida profissional dos participantes demonstra uma postura cooperativa, além de se revelarem cientes das mudanças sociais ocorridas nas últimas duas décadas. A família contemporânea redimensionou os papéis materno e paterno, não havendo mais uma hierarquia familiar, sendo divididas tanto as tarefas de cuidado dos filhos e da casa quanto as despesas financeiras. O pai passa a participar dos cuidados dos filhos e da casa, e a mãe, a colaborar financeiramente com as despesas da família (CÚNICO; ARPINI, 2013; PEREIRA, 2011; ROUDINESCO, 2003; SPENGLER, 2012).

Nos casos pesquisados, somente a esposa de Bruno não exercia atividades profissionais antes de engravidar; entretanto, mesmo assim, ele remanejou seus horários de trabalho para que pudesse estar mais presente na vida do filho, participando e desempenhando cuidados. Nos outros dois casos, as esposas são funcionárias públicas, o que conduziu Arthur, advogado, e Carlos, empresário, que modificassem suas rotinas laborais, pela flexibilidade de seus horários. As readequações de tarefas por parte dos pais, como nos dados apresentados acima, refletem o atual modelo de família contemporânea ou pós-moderna (BOSSARDI; VIEIRA, 2010; GOMES; RESENDE, 2004; RAMIRES, 1997).

\section{Percepção do entrevistado sobre a paternidade na condição de filho}

Na categoria percepção do entrevistado sobre a paternidade na condição de filho, todos os entrevistados destacam diferenças no papel exercido por eles e seu progenitor. Percebeu-se, nos relatos, aspectos próprios da questão intergeracional, a qual leva em conta o período histórico e, por sua vez, o social que influencia no comportamento do indivíduo. 
A descrição que os participantes fizeram de seus pais evidencia as características do modelo tradicional de paternidade (BOSSARDI; VIEIRA, 2010; GOMES; RESENDE, 2004; RAMIRES, 1997). Atribuem, inclusive, que a maneira como seus pais desempenhavam suas funções paternas justificava-se pelos próprios padrões comportamentais da época, distinguindose da atualidade, como se pode verificar, por exemplo, pelo relato de Arthur (37 anos): "o contexto de vida também é diferente, então, nesse sentido, eu faço coisas muito diferentes que o pai fazia. Eu trabalho e eu também cuido das coisas do meu filho, eu limpo fralda, dou banho... tudo isso com certeza meu pai não fazia". Seu depoimento revela que suas atitudes são condizentes com o modelo de paternidade contemporânea, também designada, segundo Bolze e Crepaldi (2015), de emergente. Isso porque realiza um papel mais ativo e engajado, inclusive emocionalmente, nos cuidados com o filho.

Também ficaram claros, pelos depoimentos, aspectos que evidenciam o lugar de autoridade que o pai ocupava na relação com os filhos. Arthur relata: "o pai nunca bateu nos filhos, mas ele tinha uma maneira de lidar, assim... ele sabia como passar que tava brabo". Tal aspecto é característico da paternidade tradicional, que além de servir como um modelo de poder e autoridade, também desempenha uma função educadora e disciplinadora (BENCZIK, 2011; FREITAS; COELHO; SILVA, 2007; GABRIEL; DIAS, 2011; RAMIRES, 1997).

Na narrativa de Carlos, percebe-se a evidência de ligação da paternidade ao ato de educar, instituindo regras e limites aos filhos: "E eu também sempre fui mais cobrado pelo meu pai que pela minha mãe, ela tinha o jeito dela de estimular, mas era o meu pai que cobrava, que cobrava mesmo, enfim, de fala[r] tu não estuda, como tá tuas provas”. A narrativa acima demonstra a preocupação que o pai de Carlos tinha com seu desempenho escolar, e isso pode ser entendido como instituir ao filho uma perspectiva de vida futura, garantindo-lhe segurança.

Os depoimentos dos participantes evidenciam as transformações da paternidade tradicional para a contemporânea. No contexto atual, o pai apresenta-se ativo nos cuidados dos filhos e do lar, dividindo as tarefas com a esposa, abandonando os padrões da paternidade tradicional, em que o pai basicamente apresentava-se como a figura de autoridade e era responsável pelo sustento do lar. Salienta-se que a esposa de Arthur e Carlos desempenham atividades profissionais, contribuindo financeiramente com as despesas da família.

Ao resgatar os aspectos emocionais que envolveram a relação dos entrevistados com o pai, Arthur a caracteriza como um vínculo repleto de afeto e carinho: “[...] lembro dele brincar, jogar bola e ele cuidava, tinha um carinho pelos filhos. Por mim, meus irmãos. Era uma pessoa muito carinhosa". Lembra de estar mais próximo do pai, quando mais velho - em torno de 6, 7 
anos. Seu relato apresenta a participação do pai por meio de brincadeiras e contatos afetivos, deixando claro que os cuidados em relação aos filhos e à casa eram de responsabilidade da mãe: "provavelmente ele nunca trocou uma fralda, nunca tenha dado um banho".

Tal vínculo foi descrito por Bruno da mesma forma: "Meu pai tinha um pouco de medo pelo que minha mãe fala, tinha receio de me trocar, enfim, era um pouco inseguro nesse ponto. Ele ficava mais para as atividades interativas de brincar e essas coisas, de levar passear, de levar pra lá e pra cá" (Bruno, 34 anos). As evidências mostram que os pais dos participantes não tiveram um envolvimento tão ativo em relação à divisão de tarefas nos momentos iniciais de suas vidas, comportamento contrário à paternidade desempenhada por eles com seus filhos.

Avaliando-se a paternidade sob um enfoque geracional, a tendência é que o homem repita as condutas de seu pai, pois esse é o modelo aprendido na sua relação com seu genitor. Nas dinâmicas familiares, contudo, em que a mulher tem também se ocupado de atividades profissionais, em muitos casos podendo se ausentar do trabalho profissional somente no período da licença-maternidade, o pai tem sido convocado a estar mais presente na sua relação com os filhos, dividindo também as tarefas de organização do lar com a esposa.

Pode-se perceber que, apesar de os pais dos participantes não terem estabelecido uma divisão de tarefas para os cuidados dos filhos nos momentos iniciais de suas vidas, os pais entrevistados descrevem que, em outra etapa de seu desenvolvimento, passaram muito tempo com seus pais, devido às atividades profissionais de suas mães. Bruno explicita essa condição: "a partir dos 7-8 anos, ela começou a trabalhar fora, eu lembro de passar maior parte do tempo com ele".

No relato de Carlos, o envolvimento do pai aparece um pouco mais cedo, pois a mãe era funcionária pública:

\footnotetext{
"Depois que minha mãe voltou da licença, nós tivemos creche, eu fui bem pequeno, minha irmã também. Acho que com 4, 5 meses já, depois teve uma época que tinha uma moça que ajudava meio turno que ficava com a gente, fazia comida. E quem conseguia vir dar almoço pra mim e pra minha irmã, levar na escola, era meu pai".
}

A esposa de Carlos também é funcionária pública, condição relacionada por ele como similiar à sua história de vida enquanto filho. Indica também que o desejo de ter um filho era mais presente em seu pai que em sua mãe, evocando nisso também semelhanças na sua vida e de seus genitores. Aponta-se para a semelhança-embora não descrita por ele -, de, assim como seu pai ter sido solicitado a envolver-se mais ativamente nos cuidados dos filhos em razão da profissão de sua mãe, ele também vive essa mesma situação, por conta da atividade profissional de sua esposa. Observa-se que Carlos deseja viver o modelo de relação experienciada com seu 
pai: "não sei se vou fazer muito diferente não. Depende da evolução dele, porque as coisas são muito diferentes hoje".

As autoras Bolze e Crepaldi (2015) afirmam que o comportamento de desejar repetir padrões vividos em suas relações de infância com seus pais é referenciada pela maioria dos pais, principalmente ao se tratar de aprendizagens relacionadas a valores e limites. As evidências anteriormente apresentadas corroboram com a abordagem das autoras, uma vez que os participantes afirmam desejar seguir aspectos do modelo de seus pais. Bruno indica que deseja manter atitudes como: "brincadeiras, o carinho, o amor" em sua relação com o filho.

Os relatos dos entrevistados podem estar associados a uma transição em curso da geração anterior. Com a inserção da mulher no mercado de trabalho, o pai passa a ser convocado a exercer uma paternidade mais participativa. Além do fato de os participantes descreverem o vínculo com seus pais como afetuoso, o que representaria uma característica do pai contemporâneo.

Arthur foi o participante que mais elencou diferenças de comportamento na sua relação com o pai:

"[...] eu acho que faço muita coisa diferente, eu acho assim, diferente, mas não que não tenha coisas que ele tenha me passado, o pai era um paizão, eu lembro que ele tinha uma máquina fotográfica e aí quando fazia um dia bonito, em domingo, ele ia lá e ficava tirando foto da gente. Eu tenho muita foto da gente, ele me pegando no colo. Então eu sinto que isso eu posso dizer que é um pouco parecido com o trato do pai".

Nesse caso, torna-se necessário ressaltar que o participante Arthur é alguns anos mais velho que os demais participantes, contou ser o filho mais novo de seus pais, sendo um filho “temporão", além de a família de Arthur residir no interior. Com isso, conclui-se que o modelo familiar e paterno vivido por Arthur pode ter sido diferente dos demais participantes, além de destacar que aspectos culturais - no caso, específicos de cidade do interior, também podem ter interferir nos padrões de ser pai e de ser mãe, conforme abordagem apresentada por Bossardi e Vieira (2015).

Avalia-se que todos os participantes demonstraram possuir uma relação saudável com seus pais, os quais podem ser considerados presentes e ativos. Arthur e Bruno, devido ao falecimento paterno ainda no período que estavam na adolescência, tiveram experiências junto de seus pais por um tempo menor que Carlos. A partir dos dados apresentados pelos entrevistados, pode-se perceber que mesmo essa presença física estando precocemente ausente para Arthur e Bruno, a representação psíquica de suas relações com os pais é significativamente positiva, tanto que eles reproduzem a postura presente e participativa para com seus filhos. 
Retoma-se que a conclusão apresentada a respeito da vivência dos participantes com seus progenitores, avaliando-os como pais presentes, considera a abordagem interjecional, que se orienta em entender como o modelo paterno é visto em cada época histórica e busca compreender os atributos estabelecidos como de responsabilidade ao homem e ao pai de família.

A partir das relações experienciadas, os participantes têm conseguido reproduzir os comportamentos aprendidos e também se inserirem no cenário da atualidade, o qual se configura com novas demandas, as quais exigem ao pai da atualidade um comportamento mais próximo de sua esposa, auxiliando-a e colaborando nas tarefas de cuidado dos filhos e do larreferindo-se ao cuidado dos filhos, já nos momentos iniciais de vida do bebê. Conforme Goetz e Viera (2009), é justamente essa soma de aspectos do pai tradicional - que é provedor, desempenha uma figura de autoridade e garante segurança e o envolvimento afetivo - com as características participativas do pai contemporâneo que tornam eficaz a postura paterna nos dias de hoje.

\section{Considerações finais}

Ao se considerar o objetivo deste estudo, qual seja, compreender, a partir do olhar do novo pai, o exercício da paternidade na família contemporânea, levou-se em conta os fatores que envolvem e caracterizam o pai da atualidade e a dinâmica social que abrange as relações familiares. Nesse sentido, identificou-se que os pais entrevistados reconhecem aspectos diferentes exercidos por eles com os seus filhos em relação à paternidade vivenciada com o seu progenitor, referindo que eles vêm desempenhando ativamente atividades de cuidado com os filhos desde o momento do nascimento deles. Esse fato é destacado como uma mudança de conduta e pensamento frente aos filhos, em relação ao modo como foram cuidados pelos seus pais. Os depoimentos revelam características que são consideradas próprias do novo pai, ou pai contemporâneo.

Os entrevistados indicam suas perspectivas sob as duas categorias de análise: a percepção do entrevistado na condição de filho e a percepção do entrevistado como pai. O relato dos três participantes indica que sua referência paterna se configura como participativa, embora reforcem a atuação da mãe como principal cuidadora, especialmente nos primeiros anos de vida. Eles expõem momentos de envolvimento e afetividade do pai, no entanto reconhecem que o contexto social da época reforçava um comportamento paterno oriundo dos moldes de uma 
estrutura familiar moderna, na qual o pai representava uma figura de autoridade e responsável principal pelo sustento do lar.

Deve-se levar em conta que tais perspectivas são trazidas pelos depoentes, mesmo que dois deles tenham tido uma mãe já inserida no mercado de trabalho. Isso sugere a jornada dupla da mulher, aspecto esse que, atualmente, é um dos elementos de foco e análise no cenário atual e que reforça a importância de o novo pai se perceber e de fato atuar para a construção de uma nova base familiar. O molde familiar atual deve trazer o compartilhamento de tarefas entre mãe e pai, assim como envolvimento emocional de ambos com suas crianças, possibilitando formações psíquicas nos filhos que efetuarão, de fato, novos moldes nos papeis e estruturas familiares, os quais, assim, conduzirão a uma efetiva mudança social.

Os entrevistados reconhecem sua nova postura no âmbito familiar, apontando a necessidade e a importância de maior vinculação emocional com o filho, se comparado à postura experienciada em sua própria infância. Manifestam, inclusive, sua satisfação em se relacionar de modo mais efetivo e afetuoso nos cuidados e educação dos filhos. Reforçam que já apresentavam o desejo de se tornarem pais e sinalizam que isso contribuiu para a sua efetiva participação em cuidar dos filhos. Revelam sentirem-se aptos a desenvolverem com qualidade o papel paterno.

Os resultados apontam que o compartilhamento de tarefas é fator considerado entre o casal da família contemporânea, contudo é necessário que questões sociais venham ao encontro desse novo molde familiar. Nesse sentido, faz-se necessário persistir na luta por uma educação não sexista, que permita a desconstrução de crenças e valores sobre o comportamento de homens e mulheres. Isso se estende ao mercado de trabalho e às leis que regem as diferenças de trato entre os sexos quando do nascimento de um filho. Destaca-se, nesse aspecto, a licençapaternidade. O pouco tempo de dispensa do trabalho para vivenciar a fase inicial do filho não condiz com a necessidade da família contemporânea.

Considera-se que esta investigação contribuiu para dar voz aos pais e, assim, compreender, através de seu próprio olhar, como eles têm percebido a sua atuação tanto nos cuidados dos filhos quanto na família. Reforçando a importância desse lugar ativo do pai junto aos filhos, intenciona-se estimular outros homens que, ao se tornarem pais, coloquem-se em uma posição de compartilhamento dos cuidados de seus filhos, assim como estabeleçam uma divisão nas tarefas do lar com suas esposas.

Destaca-se que, para uma compreensão mais aprofundada acerca do papel paterno na família contemporânea, se faz necessário uma investigação mais abrangente, avaliando o 
exercício da paternidade em diversos contextos socioeconômicos. Espera-se que esse trabalho contribua para as investigações sobre a paternidade e que estimule novas pesquisas a respeito da temática.

\title{
WHO IS THE NEW FATHER? CONCEPTIONS ABOUT THE EXERCISE OF PATERNITY IN THE CONTEMPORARY FAMILY
}

\begin{abstract}
The present study has as its theme the paternal role in the present time. For this, it was defined as a general concept, from the new father's perspective, the exercise of paternity in the contemporary family. An exploratory-descriptive, qualitative approach was used. The three fathers, residents of the city of Porto Alegre / RS and Metropolitan Region, received the following instruments: Screening Sheet, Sociodemographic Data Sheet and Semistructured Interview. With the data collected through the interview, an analysis was made of the content of the participants' speeches. This analysis was developed based on two categories: the interviewee's perception about the exercise of paternity and the interviewee's perception of paternity as a child. The results pointed out that to be a father, actuality, differs from the traditional models, because contemporary fathers exert a different posture with their children's experience comparised with their own experience with their fathers. The contemporary father is more envolved emotionally, more participatory and committed, dividing up childcare and housework tasks with the wife. From the look of the father, those results were reached, and it is possible to understand the exercise of paternity in the contemporary family.
\end{abstract}

Keywords: Fatherhood, New father, Contemporaneity, Family relationships.

\section{REFERÊNCIAS}

ABADE, Flávia; ROMANELLI, Geraldo. Paternidade e paternagem em famílias patrifocais. Revista Estudos Feministas, Florianópolis, v. 26, n. 2, jun. 2018.

BADINTER, Elisabeth. Um amor conquistado: o mito do amor materno. Rio de Janeiro: Nova Fronteira, 1985. Originalmente publicado em 1980.

BELTRAME, Greyce Rocha; BOTTOLI, Cristiane. Retratos do envolvimento paterno na atualidade. Barbarói, Santa Cruz do Sul, n. 32, p. 205-226, 2010.

BENCZIK, Edyleine Bellini Peroni. A importância da figura paterna para o desenvolvimento infantil. Revista Psicopedagogia, São Paulo, v. 28, n. 85, p. 67-75, 2011.

BOLZE, Simone Dill Azeredo; CREPALDI, Maria Aparecida. O pai e seus relacionamentos familiares: uma perspectiva intergeracional. In: GOETZ, Everley Rosane; VIEIRA, Mauro Luís (org.). Novo pai: percursos, desafios e possibilidades. Curitiba: Juruá, 2015. p. 31-43.

BOSSARDI, Carina Nunes; VIERA, Mauro Luís. Ser mãe e ser pai: integração de fatores biológicos e culturais. In: GOETZ, Everley Rosane; VIEIRA, Mauro Luís (org.), Novo pai: percursos, desafios e possibilidades. Curitiba: Juruá, 2015. p. 15-30.

BOSSARDI, Carina Nunes; VIEIRA, Mauro Luís. Cuidado paterno e desenvolvimento infantil. Revista de Ciências Humanas, Florianópolis, v. 44, n. 1, p. 205-221, 2010. 
CASTOLDI, Luciana; GONÇALVES, Tonantzin Ribeiro; LOPES, Rita de Cássia Sobreira. Envolvimento paterno da gestação ao primeiro ano de vida do bebê. Psicologia em Estudo, Maringá, v. 19, n. 2, p. 247-259, abr./jun. 2014.

COSTA, Jurandir Freire. Ordem médica e norma familiar. Rio de Janeiro: Graal, 1983.

CREPALDI, Maria Aparecida et al. A participação do pai nos cuidados da criança, segundo a concepção de mães. Psicologia em Estudo, Maringá, v. 11, n. 3, p. 579-587, set./dez. 2006.

CÚNICO, Sabrina Daiana; ARPINI, Dorian Mônica. A família em mudanças: desafios para a paternidade contemporânea. Pensando famílias, Porto Alegre, v. 17, n. 1, p. 28-40, 2013.

FLECK, Ana Cláudia; WAGNER, Adriana. A mulher como a principal provedora do sustento econômico familiar. Psicologia em Estudo, Maringá, v. 8, n. 1, p. 31-38, 2003.

FONSECA, Claudia. Paternidade brasileira na era do DNA: a certeza que pariu a dúvida. Cuadernos de antropología social, Buenos Aires, n. 22, p. 27-51, 2005.

FREITAS, Waglânia de Mendonça Faustino; COELHO, Edméia de Almeida Cardoso; SILVA, Ana Tereza Medeiros Cavalcanti da. Sentir-se pai: a vivência masculina sob o olhar de gênero. Cadernos de Saúde Pública, Rio de Janeiro, v. 23, n. 1, p. 137-145, jan. 2007.

GABRIEL, Marília Reginato; DIAS, Ana Cristina Garcia. Percepções sobre a paternidade: descrevendo a si mesmo e o próprio pai como pai. Estudos de Psicologia, Natal, v. 16, n. 3, p. 253-261, set./dez. 2011.

GOETZ, Everley Rosane; VIEIRA, Mauro Luís. Pai real, pai ideal. Curitiba: Juruá, 2009. GOLDANI, Ana Maria. As famílias brasileiras: mudanças e perspectivas. Cadernos de Pesquisa, São Paulo, n. 91, p. 7-22, nov. 1994.

GOMES, Aguinaldo José da Silva; RESENDE, Vera da Rocha. O pai presente: o desvelar da paternidade em uma família contemporânea. Psicologia: Teoria e Pesquisa, Brasília, v. 20, n. 2, p. 119-125, 2004.

GONÇALVES, Tonantzin Ribeiro et al. Experiência da paternidade aos três meses do bebê. Psicologia: Reflexão e Crítica, Porto Alegre, v. 26, n. 3, p. 599-608, 2013.

GRZYBOWSKI, Luciana Suárez. Famílias monoparentais: Mulheres divorciadas chefes de família. In: WAGNER, Adriana (Org.). Família em cena: tramas, dramas e transformações. Petrópolis, RJ: Vozes, 2002. p. 39-53.

KROB, Adriane Diehl; PICCININI, Cesar Augusto; SILVA, Milena da Rosa. A transição para a paternidade: da gestação ao segundo mês de vida do bebê. Psicologia USP, São Paulo, v. 20, n. 2, p. 269-291, abr./jun. 2009.

LAMB, Michael E. et al. Paternal behavior in humans. American zoologist, [S.1.], v. 25, n. 3, p. 883-894, 1985. 
NEGREIROS, Teresa Creusa de Góes Monteiro; FÉRES-CARNEIRO, Terezinha. Masculino e feminino na família contemporânea. Estudos e Pesquisas em Psicologia, Rio de Janeiro, v. 4, n. 1, p. 34-47, jun. 2004.

OLIVEIRA, Aracéles Frasson de; PELLOSO, Sandra Marisa. Paradoxo e conflitos frente ao direito de ser mulher. Acta Scientiarum. Health Sciences, [S.1.], v. 26, n. 2, p. 279-286, 2004.

PEREIRA, Rodrigo da Cunha. Pai, por que me abandonaste? In: GROENINGA, Giselle Câmara; PEREIRA, Rodrigo da Cunha (org.). Direito de família e psicanálise: rumo a uma nova epistemologia. Rio de Janeiro: Imago, 2003. p. 219-228

PEREIRA, Rodrigo da Cunha. Divórcio: teoria e prática. Rio de Janeiro: GZ, 2011.

PERUCCHI, Juliana; BEIRÃO, Aline Maiochi. Novos arranjos familiares: paternidade, parentalidade e relações de gênero sob o olhar de mulheres chefes de família. Psicologia Clínica, Rio de Janeiro, v. 19, n. 2, p. 57-69, 2007.

PETRINI, João Carlos. Mudanças sociais e familiares na atualidade: reflexões à luz da história social e da sociologia. Memorandum: Memória e História em Psicologia, Belo Horizonte, v. 8, p. 20-37, 2005.

RAMIRES, Vera Regina. O exercício da paternidade hoje. Rio de Janeiro: Rosa dos Tempos, 1997.

RAPOPORT, Andrea; PICCININI, Cesar Augusto. Apoio social e experiência da maternidade. Journal of Human Growth and Development, São Paulo, v. 16, n. 1, p. 85-96, 2006.

REIS, Erika Figueiredo. Varas de família: um encontro entre psicologia e direito. Curitiba: Juruá, 2010.

ROUDINESCO, Elizabeth. A família em desordem. Rio de Janeiro: Zahar, 2003.

SAMPIERI, Roberto Hernandez., COLLADO, Carlos Fernández; LUCIO, Pilar Baptista. Metodologia de pesquisa. 5. ed. Porto Alegre: Penso, 2013.

SILVA, José Mauricio. O lugar do pai: uma construção imaginária. São Paulo: Annablume, 2010.

SILVA, Milena da Rosa; PICCININI, Cesar Augusto. Sentimentos sobre a paternidade e o envolvimento paterno: um estudo qualitativo. Estudos de Psicologia, Campinas, v. 24, n. 4, p. 561-573, out./dez. 2007.

SOARES, Laura Cristina Eiras Coelho. A família com padrasto e/ou madrasta: Um panorama. In: BRITO, Leila Maria Torraca de (org.). Famílias e separações: perspectivas da psicologia jurídica. Rio de Janeiro: ED/UERJ, 2008. p. 81-112 
SOUZA, Carmen Lúcia Carvalho de; BENETTI, Silvia Pereira da Cruz. Paternidade contemporânea: levantamento da produção acadêmica no período de 2000 a 2007. Paidéia, Ribeirão Preto, v. 19, n. 42, p. 97-106, abr. 2009.

SPENGLER, Fabiana Marion. O fim das relações amorosas: como mediar o litígio para ter uma convivência pacífica após a separação? In: IBIAS, Delma Silveira (org.). Família e seus desafios: reflexões pessoais e patrimoniais. Porto Alegre: IBDFAM/RS, 2012. p. 243-250.

STAUDT, Ana Cristina Pontello; WAGNER, Adriana. Paternidade em tempos de mudança. Psicologia: Teoria e Prática, São Paulo, v. 10, n. 1, p. 174-185, 2008.

VIEIRA, Mauro Luís et al. Paternidade no Brasil: revisão sistemática de artigos empíricos. Arquivos Brasileiros de Psicologia, Rio de Janeiro, v. 66, n. 2, p. 36-52, 2014.

WAGNER, Adriana. Possibilidades e potencialidades da família - A construção de novos arranjos a partir do recasamento. In: WAGNER, Adriana (Org.). Família em cena: tramas, dramas e transformações. Petrópolis, RJ: Vozes, 2002. p. 23-38

Data de recebimento: 03/10/2019

Data de aceite: 19/06/2020

\section{Sobre as autoras:}

Fernanda Torzeczki Trage é Mestre em Psicologia Clínica pela Universidade do Vale do Rio dos Sinos, São Leopoldo, RS, Brasil. Endereço Eletrônico: fernandatrage@outlook.com

Tagma Marina Schneider Donelli é Professora Assistente do Programa de Pós-Graduação em Psicologia da Universidade do Vale do Rio dos Sinos, São Leopoldo, RS, Brasil. Endereço eletrônico: tagmad@unisinos.br 